\title{
What is Chromatography All About?
}

\author{
Lane C. Sander \\ National Institute of Standards and Technology, \\ Gaithersburg, MD 20899, USA \\ lane.sander@nist.gov
}

Video DOI: http://doi.org/10.18434/T4DK5T

Key words: air displacement pipette; pipette; positive displacement pipette; quantitation; volumetric transfer.

Accepted: December 1, 2016

Published: January 12, 2017

https://doi.org/10.6028/jres.122.012

\section{Summary}

Chromatography is an example of a process by which a mixture is separated into at least two fractions with different compositions. Other separation methods exist, such as distillation, recrystallization, and extraction. Chromatography is used to analyze mixtures by identifying the components, determining the amount of each present, and in some cases, purifying the separate parts. This presentation will provide a brief overview of the basic principles of liquid chromatography, with demonstrations using food dyes. The first few slides provide background material that should help to provide a basis for understanding the chromatographic separation videos. This presentation is intended to provide a nontechnical introduction to chromatography, suitable for educational purposes. ${ }^{1}$

\footnotetext{
${ }^{1}$ Contribution of the National Institute of Standards and Technology. Not subject to copyright. Certain commercial equipment, instruments, or materials are identified to specify adequately the experimental procedure. Such identification does not imply recommendation or endorsement by the National Institute of Standards and Technology, nor does it imply that the materials or equipment identified are the best available for the purpose.
} 